\title{
A Comparative Survey of the Nutrition and Physiology of Mesophilic Species in the Genus Bacillus
}

\author{
By B. C. J. G. KNIGHT AND H. PROOM \\ The Wellcome Research Laboratories, Beckenham, Kent
}

SUMMARY: Two hundred and ninety-six strains of mesophilic species of the genus Bacillus were isolated from soil and examined for the characters described principally by Smith, Gordon \& Clark (1946) as well as for some additional characters. Two hundred and forty-six belonged clearly to named species in the classification of Smith et al., thirty-two strains were clearly intermediate between two species and eight strains remained unallocated. In addition, eleven other strains appeared to represent a previously undescribed species (Proom \& Knight, 1950).

Ability to grow under strictly anaerobic conditions, to give the Gibson \& AbdelMalek (1945) test and to produce typical (lecithinase-like) or 'restricted' reactions with egg-yolk emulsion were valuable diagnostic characters in this genus.

A survey was made of the nutritional requirements of some 200 strains which included many of the newly isolated ones and representative laboratory strains. Typical nutritional patterns characterizing the species were found, with an unexpected degree of uniformity with the groups of strains examined; the number of nutritionally aberrant strains in each species was very small.

The characteristic nutritional patterns were:

B. subtilis, B. licheniformis and $B$. megatherium grew with ammonia as nitrogen source and in the absence of added growth factors.

$B$. cereus and $B$. brevis grew in absence of added growth factors but required mixtures of amino-acids instead of ammonia only.

$B$. pumilus and $B$. polymyxa both grew with ammonia + biotin, and $B$. macerans grew with ammonia + biotin + aneurin.

$B$. alvei required amino-acids + aneurin; $B$. circulans and $B$. coagulans required amino-acids and usually both aneurin and biotin; some strains of $B$. circulans had more complex requirements.

Some strains of $B$. sphaericus required amino-acids + aneurin, others required biotin as well, and all of the strains of $B$. sphaericus var. fusiformis required aminoacids + aneurin + biotin.

The strains of $B$. pasteurii were the most heterogeneous in their nutritional requirements, the components ammonium ion, amino-acids, aneurin, biotin and nicotinic acid being involved. All strains required amino-acids and aneurin; in addition, biotin or nicotinic acid and sometimes ammonium ion were required, depending on the particular strain.

There are few records of wide comparative surveys of bacterial genera which have made use not only of the classical bacteriological distinguishing tests and methods, but which have also included determinations of exact nutritional requirements, and of metabolic and serological characters. Intensive studies of particular species from these aspects have been somewhat more common; but even here comparative studies of numerous strains or clones of a species, when made, have only seldom included all the features noted above, so that well-rounded pictures of their biological properties are infrequent. The Culture Collection at these Laboratories, with the staff and services necessary for its maintenance and development, offered an opportunity to make comparative 
surveys of large groups of organisms and to examine many aspects of their physiology.

It was hoped that such comparative surveys might yield information which would help to improve the diagnosis, differentiation and classification of bacteria as they came to hand. It was further hoped that from this material might come indications of natural relationship, thus helping to make classifications somewhat less arbitrary than they tend to be at present. A long-term objective is to accumulate information which might contribute to the study of taxonomic and evolutionary problems.

A more immediate objective has been to see to what extent nutritional requirements are characteristic of species as already differentiated by the classical bacteriological tests, many of which are empirical and obviously have different weights as definitive of species characters.

This is not the place to discuss the problem of species differentiation; some pertinent examples will appear in the sequel. Indeed it might be well at this point to state our standpoint in this respect. We believe that the question of species definition and differentiation among bacteria is best not argued as a metaphysical question, $a$ priori as it were, but that the question of classification will be better worth discussion only when much more pertinent material is available. It is part of the purpose of the present work to supply some of this material. It is, of course, true that for practical purposes distinguishing characters, however empirically determined, are invaluable and that at least empirical classifications do have to be made for current use. But this does not preclude a desire to achieve better classifications, which will presumably be the better the more closely they reflect natural relationships.

In the present work two sources of organisms were used: ( $a$ ) named cultures from collections and other laboratory strains; $(b)$ strains freshly isolated from natural sources. In this way it was possible to see whether long-continued laboratory culture had modified any characters and to assess the homogeneity of groups of freshly isolated strains, which presumably represented the organisms occurring in nature.

The genus Bacillus, excluding thermophilic organisms, was chosen for our first survey for a number of reasons. It includes one organism frankly pathogenic to man and some animals, namely $B$. anthracis, one which is pathogenic for bees, $B$. larvae, a number of species of interest as producers of antibiotics (e.g. B. subtilis, B. brevis, B. polymyxa, B. licheniformis, B. circulans), and is a relatively well-defined genus. The investigations of Gibson (1934 $a, b ; 1935 a, b$; 1944) and of Smith et al. (1946) provided a firm basis from which to start. The classification introduced by Smith et al. (1946) and used in Bergey's Manual of Determinative Bacteriology (6th edition, 1948) divides the genus into three groups on the basis of the morphology of the spores and sporangia, and into fifteen species and seven varieties on physiological grounds. This contrasts with the 157 differently named 'species' which were examined by Smith et al. and with the 26 pages of names and references of unallocated and insufficiently described strains which are recorded in the appendix to the genus in Bergey's Manual. We have found the Smith et al. (1946) classification workable and 
useful, and have used it in identifying our newly isolated strains. These strains were then examined by tests not used by these workers, and in many cases the nutritional requirements of both laboratory and newly isolated strains were examined. On the basis of the results, the classification of the genus as it stands at present was then examined.

The exact nutrition of species of the genus Bacillus has, with few exceptions, been little studied; and no extensive comparative examination has been made. There are references in the earlier literature to the cultivation of one or a few strains of certain organisms, e.g. B. subtilis, on very simple media (e.g. ammonia or asparagine, glucose and salts), but when much of this work was done the role of very low concentrations of certain substances (essential metabolites) in promoting growth was not adequately recognized. It is not therefore always certain that the simple 'defined' media used were, in fact, free from organic growth factors, such as biotin, especially when the 'defined' media contained a natural product like asparagine, sucrose or glucose. More recently, since the recognition of the role in nutrition of various essential metabolites of the vitamin B group, this point has usually been recognized and adequately controlled in nutritional studies.

The nutrient requirements of certain strains of $B$. anthracis were studied by Gladstone (1939) and by Brewer, McCullough, Mills, Roessler, Herbst \& Howe (1946). Since we have not studied this organism their observations may be summarized here. Gladstone used eight strains of $B$. anthracis obtained from the National Collection of Type Cultures; six grew well on a medium containing an array of amino-acids, salts and glucose; but no growth factors of the vitamin B group appeared to be needed. Gladstone (private communication, 1949) on repeating his earlier work with some six strains (including one or two of the earlier collection) found a requirement for aneurin and adenosine+adenylic acid. The adenosine and adenylic acid were important in initiating growth. Brewer et al. (1946) found that the strain 'Vollum, M-36' required aneurin in addition to a collection of amino-acids, salts, etc.; aneurin was the only growth factor required. Thus $B$. anthracis appears to require a collection of amino-acids and that at least some strains require aneurin, with adenosine and/or adenylic acid, the latter possibly as growth initiators or stimulators.

Other organisms of the genus Bacillus which have been examined for nutritional requirements and in which collections of strains were used include $B$. alvei and B. para-alvei (Katznelson \& Lochhead, 1947), B. macerans and ' $B$. acetoaethylicus' (Katznelson, 1944). Eight strains of $B$. larvae were examined by Lochhead (1942) and found to require aneurin and peptone; the peptone may have been a source of other nutrients besides amino-acids. The study of B. larvae was extended by Katznelson \& Lochhead (1948), who found that the intact aneurin molecule was required by most strains, which also required various purines and pyrimidines; and some strains required strepogenin. We have not examined strains of $B$. larvae in the present work. Recently Cleverdon, Pelczar \& Doetsch $(1949 b)$ examined the vitamin requirement of numerous strains of stenothermophilic $\left(55-65^{\circ}\right)$ organisms of the genus 
Bacillus. With an acid-hydrolysed casein basal medium, the essential metabolites required as nutrients were aneurin, biotin and nicotinic acid. We have not examined organisms growing above $45^{\circ}$; the results of Cleverdon et al. $(\mathbf{1 9 4 9} b)$ are considered below. Other references to nutritional requirements in this genus are cited below. In the present paper are recorded the results of an examination of the nutrition of some 200 newly isolated and laboratory strains.

\section{EXPERIMENTAL}

\section{The isolation of strains of Bacillus from soil}

Isolations from soil samples. Some hundred samples of soil from widely separated localities in the British Isles, and a few specimens from Europe, were examined. In order to make the study as representative as possible we isolated only one culture of any particular species from any one sample of soil; 296 strains were thus isolated. The pre-treatment of the soil and the use of differential media had a marked effect on the kinds of species which were isolated. The numbers and variety of species varied with the soil samples, but not as much as was expected.

To $10 \mathrm{ml}$. of medium contained in a $6 \times \frac{5}{8}$ in. test-tube sufficient soil was added to give a total volume of $c .15 \mathrm{ml}$. The tube was well shaken, and a loopful of suspension plated by streaking on an appropriate agar medium. When a tube of soil suspension was to be heated a thermometer was placed in the tube, or in a control tube containing the same volume of tap water, to ensure that the sample reached, and was kept at, the desired temperature for the appropriate time. Temperatures were controlled to $\pm 1^{\circ}$.

After incubation of the inoculated plates single colonies were transferred to nutrient agar slopes; at the same time Gram-stained preparations were examined. After 2 days' incubation at 28 or $37^{\circ}$ sporulating cultures were purified by plating. When a culture morphologically resembled the vegetative form of members of the genus it was left at room temperature, was examined at intervals for sporulation and discarded if this did not occur within 2 weeks. Of the new isolates obtained as described 10-20\% were asporogenous and were discarded. Special media alleged to induce sporulation made little difference to the number of asporogenous forms encountered and were not used routinely.'

\section{The species obtained by the differential isolation techniques}

The results obtained by different methods of treating soil suspensions and plates may be summarized as follows:

(a) Direct plating of soil suspension in broth on nutrient agar followed by incubation at $37^{\circ}$ for 2 days gave predominantly $B$. subtilis to the exclusion of other organisms. An occasional colony of $B$. circulans, B. megatherium or B. cereus was obtained.

(b) Soil suspension in broth plated on nutrient agar and incubated at $28^{\circ}$ instead of $37^{\circ}$ yielded $B$. cereus var. mycoides and $B$. subtilis as predominant organisms.

(c) Soil suspension in broth heated at $70^{\circ}$ for $10 \mathrm{~min}$. followed by plating on nutrient agar and incubation at $37^{\circ}$ gave a mixture of $B$. subtilis and 
B. circulans. Incubation at $28^{\circ}$ instead of $37^{\circ}$ gave a mixture of $B$. cereus var. mycoides and $\boldsymbol{B}$. subtilis.

$(d)$ Soil suspension in broth heated at $70^{\circ}$ for $10 \mathrm{~min}$., incubated in broth at $28^{\circ}$ for 2 days, plated on nutrient agar and incubated at $37^{\circ}$ for 2 days, gave a mixture of $\boldsymbol{B}$. cereus and $\boldsymbol{B}$. megatherium with occasional colonies of $B$. subtilis. Plating on nutrient agar and incubation at $28^{\circ}$ instead of $37^{\circ}$ gave a mixture of $B$. cereus and $B$. megatherium with some colonies of $B$. cereus var. mycoides and $B$. subtilis.

(e) Soil suspension in distilled water incubated at $37^{\circ}$ for $\mathbf{3}$ days, followed by plating on nutrient agar and incubation at $37^{\circ}$ produced a very mixed collection of colonies. B. subtilis, B. cereus and $B$. megatherium, although present, were fewer in number. $B$. pumilus and $B$. circulans, with occasional colonies of $\boldsymbol{B}$. brevis, B. macerans, B. alvei (once) and B. sphaericus, were observed.

$(f)$ Soil suspension in milk incubated for 3 days at $50^{\circ}$ and plated on nutrient agar at $45^{\circ}$ also gave a varied collection of organisms from which $B$. coagulans could be readily isolated.

(g) Soil suspension in $3.0 \%$ glucose broth was heated at $65^{\circ}$ for $10 \mathrm{~min}$., incubated at $28^{\circ}$ for 3 days, plated on nutrient agar and incubated at $28^{\circ}$. Selected colonies were grown in glucose broth and those cultures which produced acid and gas were plated on nutrient agar. This gave strains of B. polymyxa.

(h) Soil suspension in urea (10 or $2.0 \%$ ) broth was incubated for 2 days at $28^{\circ}$ and plated on nutrient agar containing either 10 or $2.0 \%$ urea. This treatment suppressed all organisms other than those of morphological group 3 , and strains of $B$. sphaericus together with its varieties, $B$. pasteurii and occasional strains of $B$. lentus, were isolated.

After identification the new isolates were stored as freeze-dried desiccates.

\section{Bacteriological methods used in examining the cultures}

In order to compare our results with those of Smith et al. (1946) we used bacteriological media that resembled theirs as closely as practicable. Our nutrient broth containing $c .3 \mathrm{~g}$. $\mathrm{N} / \mathrm{l}$. was prepared by the addition of papain digest of horse muscle containing $c .1 .5 \mathrm{~g}$. N/l. to a water extract of fresh horse muscle. Nutrient agar was prepared by adding $\mathbf{1 . 2} \%$ agar (Davies Gelatin (N.Z.) Ltd.) to this nutrient broth.

Microscopical examination. Organisms grown on nutrient agar were Gramstained and examined microscopically. The size of vegetative rods and of spores was not usually measured. Although typically large- and small-cell species exist it was observed that the effect of different media and strain variations made such measurements of little value in identification. There was, however, one notable exception. Smith et al. (1946) observed that B. megatherium and $B$. cereus could be distinguished from other members of morphological group 1 (see below) by the fact that the width in stained preparations of the vegetative rods of these two organisms was $0.9 \mu$. or greater; this we amply confirmed. The position and shape of the spore, the thickness of the spore-wall and the shape of the sporangium were found by Smith et al. to be of considerable value 
in classification. We found little difficulty in allotting a new isolate to one or other of the three main morphological groups of the classification of Smith et al. These are: group 1, in which the sporangium is only slightly swollen, or not at all, by a thin-walled oval spore; group 2 , in which the sporangium is swollen by a thick-walled oval spore; group 3 , in which the sporangium is swollen by a thick-walled spherical spore.

Smith \& Clark's (1937) observation that B. megatherium and B. cereus, in contradistinction to other species, when stained by Sudan III showed large fat globules, was confirmed. The later observation of Smith et al. (1946) that when stained by Hartman's (1940) method all members of the genus Bacillus showed stored fat, did not, in our experience, diminish the value of the original observation. As a routine we used the method described by Burdon, Stokes \& Kimbrough (1942). With this technique $B$. cereus and $B$. megatherium showed many large fat globules, while other species had none or only a few small fat globules.

Macroscopical examination. The colonial appearance on nutrient agar and the nature of the growth on nutrient agar, glucose nitrate agar, glucose nutrient agar and potato, and in nutrient broth, were observed. The appearance of the growth and the colonial form were too variable to be of much use in the identification of species. The rapidity of dissociation on artificial media and the occurrence of numerous varieties, e.g. rough, smooth, mucoid, sporogenous, asporogenous, each with a distinct colonial appearance, is well known. It is illustrated by recent publications by Ledingham, Adams \& Stanier (1945) and by Francis \& Rippon (1949), who described such variants in B. polymyxa. It is, however, our impression that on first isolation from the soil each species has a predominant colonial form, suggesting that in the soil one variant is predominant. We were unable to confirm the observation of Smith $e$ al. that the nature of the growth on glucose nitrate agar was of value in identification.

Physiological reactions. Strains were examined for the production of acid and gas from glucose, arabinose and xylose. In view of the observations of Smith et al. (1946) these sugars were, with a few exceptions, the only ones used in routine examination. Three types of sugar media were tried: medium $a$, peptone water; medium $b$, a liquid medium in which the sole source of nitrogen was ammonia; medium $c, 1.2 \%$ agar slopes made with medium $b$. These media were inoculated with a loopful of nutrient agar culture. The results obtained with medium $a$ were irregular because of the ammonia produced from the peptone by many of the species. Medium $b$ was inferior to $c$ and often failed to support adequate growth. Medium $c$ gave the most reproducible results. Many of the species tested required preformed amino-acids and specific growth factors as nutrients, and these substances were no doubt supplied by carry-over in the inoculum and as impurities in the agar.

Hydrolysis of casein, gelatin and starch was determined by the plate methods of Smith et al. (1946). The urea medium of Christensen (1946) containing phenol red indicator was used for the detection of urease.

The Voges-Proskauer (VP) reaction (acetylmethylcarbinol production) was determined by the method of Smith et al. (1946) after incubation at $28^{\circ}$ for 
2 and 6 days, except in the case of $B$. coagulans when incubation was carried out at $45^{\circ}$.

Reduction of nitrate to nitrite, utilization of citrate, growth in broth containing $4 \% \mathrm{NaCl}$ ( $\mathrm{NaCl}$ broth) and growth on nutrient agar at $\mathrm{pH} \mathrm{6.0} \mathrm{were} \mathrm{all}$ examined. All strains were tested for production of catalase, ability to grow anaerobically on nutrient agar in McIntosh-Fildes anaerobic jars, and for the production of gas from glucose under the semi-anaerobic conditions of the Gibson \& Abdel-Malek (1945) test.

Tests for lecithinases or other enzymes visibly affecting egg-yolk emulsion were made on nutrient agar plates containing $10 \cdot 0 \%(\mathrm{v} / \mathrm{v})$ of egg-yolk emulsion (Macfarlane, Oakley \& Anderson, 1941). Two types of reactions were observed: (i) the reaction characteristic of such organisms as $\mathrm{Cl}$. perfringens and $\mathrm{B}$. cereus which give a zone of opalescence extending usually well beyond the area of growth, indicating easily diffusible enzymes. In these two organisms the effect is known to be due to $\mathbf{C}$ type lecithinases; (ii) a fainter reaction which was restricted to the medium immediately beneath the colony or streak of growth and was in general visible only when the growth was scraped away. This type of egg-yolk reaction was produced by $B$. pumilus, B. polymyxa, $B$. macerans, $B$. alvei and $B$. brevis, and will be referred to as a 'restricted' reaction. It may or may not be due to a lecithinase.

\section{Nutritional requirements}

General. The organisms were cultivated in $c .5 \mathrm{ml}$. lots of medium in $6 \times 1$ in. rimless boiling-tubes closed by loosely fitting aluminium caps. These tubes were incubated in a sloped position at about $10^{\circ}$ from the horizontal, thus permitting relatively good aeration for these static cultures; the liquid medium was about $12 \mathrm{~mm}$. thick at the deepest part and became progressively shallower towards the mouth of the tube.

The usual precautions to avoid contamination by traces of unwanted nutrients were adopted. All glassware was cleaned with chromic-sulphuric acid mixture, thoroughly washed with running tap water and finally with running distilled water. All chemicals were of highest commercial grade and further purified if necessary.

Inoculation and serial subcultivation. The starting-point for cultivation was a tube of freeze-dried cultures from the Collection. The culture was seeded into nutrient broth and from that to agar slopes. Since ten to twenty tubes of any given culture were freeze-dried at any one time, replicate tubes were always available for reference. The initial inoculum into a defined medium was taken from an agar slope by a small loop. Subsequent inoculations into chemically defined media were made either with the small loop or by a drop $(0.05 \mathrm{ml}$.) of a diluted cell suspension of just visible turbidity. The objective in serial subcultivation in chemically defined media was, of course, to eliminate positive growth due to a carry-over of nutrient from the previous tube. With highly potent compounds such as biotin several subcultures were sometimes needed before no growth occurred in a biotin-deficient medium with an organism which proved later to be unable to synthesize biotin. During serial 
subcultivation in minimal or nearly minimal media the possibility of selecting organisms which were better synthesizers of essential metabolites not present as nutrients was always borne in mind. A simplified medium arrived at by serial subcultivation in progressively simpler media was always tested for ability to support the growth of the original strain by going back to inocula from an agar slope which itself had been inoculated with a freshly revived desiccate. The latter procedure also acted as a check on the possibility that a contaminated culture had been carried forward. The usual signs of contamination (change in macroscopic and microscopic appearance of the culture, sudden ability to grow in a deficient medium, etc.) were carefully watched for, but with these closely related species could not be relied upon to exclude contamination. In critical cases the organisms obtained growing on a simplified defined medium after serial subculture were re-identified, as a further check.

\section{Determination of nutritional efficacy of defined media}

The efficacy of defined media in supporting growth was determined by visual observation of the sets of tubes, with readings at $24 \mathrm{hr}$. intervals for periods usually up to 8-4 days. The method of study usually took the form of a set of tubes of defined media, which differed from one another by the presence of one or more growth factors or of different $\mathrm{N}$ sources, the whole set being inoculated at the same time with the same inoculum. Subsequent visual inspection then showed the relative amounts of growth which occurred in the different tubes of a set of media of different compositions. The relative amounts of growth were scored in such measures as tr. (trace), sl. (slight),,, \pm+++ , +++ . This way of observing relative amounts of growth was adequate for determining response to various components of the media, since it was being used, in effect, as a qualitative determination of the ability of given substances to satisfy nutrient requirements. No attempt was made to determine optimal, but only minimal or near minimal nutrient requirements. In the present work, too, we were content to find that aneurin, for example, was an adequate nutrient, without going on to find whether the intact molecule of aneurin was essential or whether the vitamin thiazole + pyrimidine, or one of these components, was adequate. That is, in general we have not determined degrees of biosynthetic ability, but have sought to define nutritional requirements in terms of nutritionally adequate known compounds and not necessarily in terms of minimal requirements.

\section{The nutrients examined}

The nutritional requirements chiefly examined were:

(a) Sources of nitrogen. Ammonium ion, certain mixtures of amino-acids, and acid-hydrolysed casein were used. The chief requirements examined were ability to use ammonium ion and if not, ability to use acid-hydrolysed casein, i.e. a collection of most of the naturally occurring amino-acids of protein. The latter was sometimes fortified by addition of tryptophan, cystine (or cysteine) and threonine. Only in a few cases was the casein-hydrolysate replaced by mixtures of known amino-acids; in general we did not study exact amino-acid requirements. 
(b) Essential metabolites, mainly of the vitamin $B$ group. Nutrient requirements satisfied by aneurin, biotin, nicotinic acid, pantothenic acid, pyridoxin, folic acid or riboflavin were examined as a routine. From among these components adequate nutrients were, with few exceptions, found for our strains.

(c) Glucose $(3 \%, w / v)$ was added to all media, unless otherwise mentioned. Other utilizable carbon sources, other than amino-acid mixtures, were not used.

(d) Salt composition and trace elements. This category of nutrient requirements was not analysed. The usual salts and known traces of various elements were present in the media used and kept relatively constant. The criterion was that growth occurred, although of course not necessarily optimal growth, but enough to make clear the effect of omitting any component from a given medium.

For certain species a special addition of $\mathrm{NaCl}$ was required (see below). In many batches of acid-hydrolysed casein medium less complex salt mixtures were added than when using the ammonia basal medium. The acid-hydrolysed caseins were commercial products and were by no means salt-free. Thus, though they added unknown elements to the media, they were adequate for the purposes for which they were intended, namely, as a source of a collection of L-amino-acids in the proportions as in a natural protein, and free at least from growth factors of the vitamin B group. In critical cases special microbiological tests for absence of specific essential metabolites were made; and the casein hydrolysate was replaced in some cases by an amino-acid mixture of known composition.

\section{Composition of media}

We used two basal media: (a) ammonia basal medium, (b) acid-hydrolysed casein basal medium, to which were added sterile solutions of glucose (to final concentration $3 \%$ ) and growth factors as required. In some cases mixtures of amino-acids were used instead of ammonia or hydrolysed casein.

Ammonia basal medium. This consisted of: $\mathrm{KH}_{2} \mathrm{PO}_{4}, 1.5 \mathrm{~g}$.; $\left(\mathrm{NH}_{4}\right)_{2} \mathrm{HPO}_{4}$, $7 \cdot 0$ g.; $\mathrm{MgSO}_{4} .7 \mathrm{H}_{2} \mathrm{O}, 0.5 \mathrm{~g} . ; \mathrm{CaCl}_{2} .2 \mathrm{H}_{2} \mathrm{O}, 0 \cdot 3 \mathrm{~g}$.; $\mathrm{MnSO}_{4} .4 \mathrm{H}_{2} \mathrm{O}, 40 \mathrm{mg}$; $\mathrm{FeSO}_{4} .7 \mathrm{H}_{2} \mathrm{O}, 2.5 \mathrm{mg}$; ammonium molybdate, $2.0 \mathrm{mg}$. These salts were dissolved together in distilled water $(11$.) and the $\mathrm{pH}$ adjusted to $\mathrm{pH} 7 \cdot 0$. The solution was boiled, filtered and tubed in $5 \mathrm{ml}$. lots and sterilized by autoclaving for $20 \mathrm{~min}$. at $115^{\circ}$.

The casein basal medium was made from acid-hydrolysed casein vitamin-free (Ashe Laboratories Ltd., Victoria Street, London, S.W. 1, and Allen and Hanbury's Ltd., London, E. 2). Samples were analysed on receipt for moisture, total ash, total nitrogen, $\mathrm{Cu}$ and $\mathrm{Fe}$, and used so as to give a total nitrogen content of $0.1 \%$ in the finished medium, which had the following composition: sufficient acid-hydrolysed casein powder; tryptophan, $\mathbf{0} \cdot \mathbf{l}$ g. ; cystine, 0.01 g.; $\mathrm{K}_{2} \mathrm{HPO}_{4}, 5.0 \mathrm{~g}$; $\mathrm{NaCl}, 1.0 \mathrm{~g}$. These components were dissolved in $1 \mathrm{l}$. distilled water, the $\mathrm{pH}$ adjusted to $\mathrm{pH} 7$, boiled, filtered, tubed in $5 \mathrm{ml}$. lots and sterilized by autoclaving $10 \mathrm{~min}$. at $110^{\circ}$.

Medium 7 AA. Ammonia basal medium was supplemented with the following seven amino-acids in the concentrations shown (in $\mathrm{mg} / \mathrm{ml}$.): L-asparagine, 
0.04; L-proline, 1.0; L-leucine, 1.5; DL-alanine, 0.35; L-glutamic acid, 0.5; DL-serine, $0 \cdot 2$; DL-methionine, $0 \cdot 1$.

Medium 14AA. Ammonia basal medium was supplemented with the following fourteen amino-acids in the concentrations shown (in $\mathrm{mg} . / \mathrm{ml}$.): DLalanine, $0 \cdot 08$; DL-aspartic acid, 0.10; L-arginine $\mathrm{HCl}, 0 \cdot 16$; L-cysteine $\mathrm{HCl}, 0 \cdot 25$; L-glutamic acid, 0.50; glycine, 0.08; L-histidine $\mathrm{HCl}, 0.16$; L-leucine, 0.10; DL-methionine $0 \cdot 16$; DL-phenylalanine, 0.20; DL-serine, 0.08; DL-tryptophan, 0.20; L-tyrosine, 0.14; DL-valine, 0.32 (cf. Katznelson \& Lochhead, 1947).

Glucose. A $50 \%(\mathrm{w} / \mathrm{v})$ solution was sterilized by steaming $\left(100^{\circ}\right)$ for $30 \mathrm{~min}$. on 2 successive days. A volume of $0.3 \mathrm{ml}$. of this solution was added per $5 \mathrm{ml}$. basal medium.

Grozoth factors. Stock solutions were made up and sterilized by autoclaving $\left(20 \mathrm{~min}\right.$. at $\left.115^{\circ}\right)$ except in the case of thermolabile compounds which were sterilized by filtration through Ford S.B. Sterimats, using Pyrex glass filterholders (Knight \& Fildes, 1936). The following final concentrations in media were used: biotin, $1 \mathrm{~m} \mu \mathrm{g} . / \mathrm{ml}$.; folic acid, $2 \mathrm{~m} \mu \mathrm{g} . / \mathrm{ml}$.; riboflavin, $0 \cdot 1 \mu \mathrm{g} . / \mathrm{ml}$.; aneurin, nicotinic acid, pyrodoxin $\mathrm{HCl}$ and $\mathrm{Ca}$ pantothenate all at $0 \cdot 5 \mu \mathrm{g} . / \mathrm{ml}$. Stock solutions of fifty times these concentrations were made up and $0 \cdot 1 \mathrm{ml}$. added per $5 \mathrm{ml}$. of basal medium as required.

\section{RESULTS}

In reporting our results here 'new isolate' means 'newly isolated strain'; it is part of our object to compare as many properties as possible of such newly isolated strains with those of laboratory strains. The results are recorded species by species, in the order adopted in Bergey's Manual, 6th ed. (1948). The whole survey is summarized in Tables 6 and 7. Strain numbers preceded by $\mathrm{CN}$ refer to the catalogue number in the Culture Collection at these laboratories; numbers preceded by ATCC are the American Type Culture Collection numbers and those prefaced by NCTC are from the National Collection of Type Cultures (Colindale).

\section{Bacillus subtilis}

Fifteen new isolates were studied in detail. Smith et al. (1946) considered the following characters as the more important in identifying this species: the morphology, in particular a width of vegetative rod of $<0.9 \mu$; the growth on glucose agar, glucose nitrate agar, tyrosine agar and potato; positive VP reaction; acid without gas from glucose, arabinose and xylose; hydrolysis of starch, gelatin and casein; the reduction of nitrate to nitrite. They separated this species from $B$. pumilus because $B$. pumilus did not hydrolyse starch or reduce nitrate to nitrite.

Apart from finding that growth on glucose nitrate agar and glucose nutrient agar was of little value in identification, the observations of Smith et al. were confirmed. In addition, all these strains were strictly aerobic and did not give a positive Gibson \& Abdel-Malek (1945) reaction.

Nutrition. Twenty-six of twenty-seven strains of $B$. subtilis grew at $37^{\circ}$ with ammonia as sole source of nitrogen and required no growth factors. 
Fifteen were new isolates and twelve were laboratory strains, including two from culture collections $(C N$ 1707 $=$ NCTC no. 2586; CN 2189=ATCC no. $6638=$ N. R. Smith no. 281).

The one exceptional strain (CN 2745) failed to grow with ammonia but grew when given proline, leucine, alanine, serine and asparagine. This amino-acid mixture was not minimal however; omission of asparagine delayed growth for $24 \mathrm{hr}$. and omission of alanine in presence of asparagine prevented growth, at least up to $96 \mathrm{hr}$. Serine appeared to be an absolute requirement in the above mixture.

Bacillus subtilis var. aterrimus and Bacillus subtilis var. niger

The characters used to differentiate these two varieties are described in Smith et al. (1946; cf. Bergey, 1948, p. 706). The aterrimus variety forms a black pigment on carbohydrate medium, the variety niger only on media containing tyrosine.

The two strains of aterrimus and the one of niger examined grew on the ammonia basal medium and needed no added growth factors. The strain of aterrimus, CN 2743, was identified as such in these Laboratories, and was among a collection of laboratory strains received as $B$. subtilis. The other strain (CN 2192) of aterrimus was ATCC no. 6464 (=N. R. Smith no. 275). The single strain of niger was likewise from the ATCC being no. $1972(=N$. R. Smith no. 650). Nutritionally, therefore, these three strains were indistinguishable from typical strains of $B$. subtilis.

\section{Bacillus licheniformis}

Gibson (1944) showed that it was possible to differentiate certain strains of a subtilis-like organism sharply from $B$. subtilis proper, that the correct designation for what appeared to be a distinct species was the new combination $\boldsymbol{B}$. licheniformis (Weigmann) Gibson, and that among the most important characters of $\boldsymbol{B}$. licheniformis, differentiating it from $\boldsymbol{B}$. subtilis, were the ability to grow anaerobically and to give a positive Gibson \& Abdel-Malek (1945) reaction.

The metabolism of strains of $\boldsymbol{B}$. licheniformis has been considerably studied because of the striking and characteristic products formed from glucose under anaerobic conditions, namely, 2, 3-butanediol and glycerol in approximately equimolar concentrations. The relatively high concentration of glycerol formed is rare in bacterial metabolism. Organisms with this characteristic metabolism were used under the name of $B$. subtilis, Ford's type or Ford's strain, and compared with B. subtilis, Marburg type, for example by Blackwood, Neish, Brown \& Ledingham (1947). The typical metabolism of the Ford type strains (=B. licheniformis) was quite different from that of the Marburg type strains (=B. subtilis). These authors supported the suggestion of Gibson that these Ford type strains deserved separate species rank. Smith et al. (1946) did not study any organisms under the name $B$. licheniformis nor did they comment on the characteristics which might entitle this organism to specific rank. Bergey (1948) refers to $\boldsymbol{B}$. licheniformis only in the appendix to the genus; but it is 
clear from the dates of the references there given that the subsequent strong evidence accumulated by Gibson (1944) and by Blackwood et al. (1947) appeared after the relevant portion of Bergey's Manual had been prepared.

We studied twelve strains of $B$. licheniformis having the characters described by Gibson (1944); four of these strains were newly isolated and eight were from the Microbiological Research Department (Ministry of Supply), Porton. In view of the differential importance of the ability to grow strictly anaerobically, which these twelve strains possessed, and because of the unusual anaerobic dissimilation of glucose, we support the assignment of this organism to specific rank.

Nutrition. All twelve strains grew with ammonia as sole source of nitrogen and required no growth factors. Thus nutritionally these strains were indistinguishable from typical strains of $B$. subtilis so far as nitrogen source and non-requirement of growth factors was concerned. Since, however, licheniformis strains grow anaerobically in ordinary media (subtilis strains cannot) and have a characteristic anaerobic glucose dissimilation, nutritional differences in utilizable carbon and energy sources could undoubtedly be shown.

\section{Bacillus pumilus}

Twelve new isolates were studied in detail. Smith et al. (1946) considered the following characters to be important in identifying this species: the morphology, including a width of vegetative rod of $<0.9 \mu$.; positive VP reaction; production of acid from glucose, arabinose and xylose; failure to hydrolyse starch; failure to reduce nitrate.

These properties were observed with all our new isolates except that a few failed to ferment arabinose or xylose. All these strains grew only aerobically, did not produce urease and grew in $4.0 \% \mathrm{NaCl}$ broth and on nutrient agar at pH 6.0. All strains produced a 'restricted' egg-yolk reaction, in contradistinction to $B$. subtilis, which was consistently negative.

Nutrition. Twenty-one strains were examined (eleven new isolates and ten laboratory strains which included ATCC no. 7061 =N. R. Smith no. $272=C N$ 2200). With two exceptions these strains grew on ammonia basal medium + DLbiotin. The exceptions were CN 807, which would not grow with ammonia + biotin but did so with glutamic acid + biotin, and CN 2746, which similarly would not grow with ammonia but did so when given asparagine +leucine+ biotin. These two strains were thus like the other nineteen in having a nutrient requirement satisfied by biotin; but their ability in amino-acid synthesis was more restricted, since they could not use only ammonia for that purpose (Table 1).

The specificity of the biotin requirement was examined only with strains CN 787, 2731, 2732, 2783, 2735 and 2736. All strains used DL-biotin and DL-Oheterobiotin. But strain CN 2733 could not utilize DL-desthiobiotin, whereas all the others of this group of strains did so. Thus CN 2733 is a strain in which the biosynthesis of biotin is blocked at least at the conversion of desthiobiotin to biotin, whereas the block occurs earlier in the other strains. The utilization of other possible precursors in biotin synthesis is being further examined. 
Table 1. Comparison of nutritional and other characters of Bacillus subtilis, B. licheniformis, B. pumilus and B. subtilis/pumilus intermediates

\begin{tabular}{|c|c|c|c|c|c|c|c|c|}
\hline \multirow[b]{2}{*}{ Organism } & \multirow[b]{2}{*}{$\begin{array}{l}\text { No. of } \\
\text { strains }\end{array}$} & \multirow[b]{2}{*}{$\begin{array}{l}\text { An- } \\
\text { aerobic } \\
\text { growth }\end{array}$} & \multirow{2}{*}{$\begin{array}{l}\text { Gibson } \\
\& \\
\text { Abdel- } \\
\text { Malek } \\
\text { reaction }\end{array}$} & \multirow[b]{2}{*}{$\begin{array}{c}\text { Nitrate } \\
\text { reduc- } \\
\text { tion }\end{array}$} & \multirow[b]{2}{*}{$\begin{array}{l}\text { Starch } \\
\text { hydro- } \\
\text { lysis }\end{array}$} & \multicolumn{3}{|c|}{ Nutrient requirements } \\
\hline & & & & & & $\begin{array}{l}\text { Am- } \\
\text { monia }\end{array}$ & $\begin{array}{l}\text { Amino- } \\
\text { acids }\end{array}$ & Biotin \\
\hline B. subtilis & $\begin{array}{r}26 \\
1\end{array}$ & - & - & + & + & $\stackrel{+}{-}$ & $\overline{+}$ & $\overline{-}$ \\
\hline B. licheniformis & 12 & + & + & + & + & + & - & - \\
\hline B. pumilus & $\begin{array}{r}19 \\
2\end{array}$ & $\overline{-}$ & - & $\overline{-}$ & $\overline{-}$ & \pm & $\bar{t}$ & + \\
\hline Intermediates: & & & & & & & & \\
\hline CN 1582 & . & - & - & - & + & + & - & - \\
\hline CN 1583 & . & - & - & - & + & + & - & - \\
\hline CN 2499 & . & - & - & - & + & + & - & $t$ \\
\hline CN 2549 & . & - & - & - & + & + & - & + \\
\hline
\end{tabular}

One of these strains (CN 787) was received labelled ' $B$. subtilis'. When it failed to grow on ammonia media without biotin, but grew when biotin was added, the culture was re-examined and found to be a typical pumilus, being unable to hydrolyse starch or reduce nitrate. Thus the nutritional character drew attention to an incorrect identification.

\section{Bacillus subtilis/pumilus intermediates}

Four cultures, all new isolates, which were intermediate in character between $\boldsymbol{B}$. subtilis and $\boldsymbol{B}$. pumilus were examined. The differentiation of $\boldsymbol{B}$. subtilis from $B$. pumilus at present depends on the hydrolysis of starch and the reduction of nitrate by $B$. subtilis, whereas $B$. pumilus does neither (Smith et al. 1946). These four intermediate strains all hydrolysed starch, like B. subtilis, but, like $B$. pumilus, did not reduce nitrate. The egg-yolk reactions were negative. Two of these strains (CN 1581 and 1582) grew with ammonia alone, i.e. like $B$. subtilis, while two (CN 2499 and 2459) grew only on ammonia basal+biotin, i.e. they were like typical $B$. pumilus strains in nutritional requirements.

Thus nutritionally these 'intermediates' corresponded with the typical nutrition of one or other of the two relevant species (see Table 1).

\section{Bacillus coagulans}

Fifteen new isolates were studied in detail. Smith et al. (1946) considered the following characters to be the more important in identifying this species: better growth at $45^{\circ}$ than at $37^{\circ}$ or $28^{\circ}$; positive VP reaction; starch hydrolysed; no hydrolysis of gelatin; weak hydrolysis of casein; heavy growth on glucose broth with a resultant $\mathrm{pH}$ of about 4.0 after 7 days and with the rapid evolution of gas with metallic iron. These characters were found in all fifteen new isolates, although the better growth observed at $45^{\circ}$ might be a reflexion of our method of isolating the organisms from the soil. Smith et al. state that this organism usually produces acid from arabinose but not from xylose. With 
our new isolates this property was very variable; ten produced acid from both arabinose and xylose and one did not produce acid from either sugar.

All the strains grew anaerobically, did not produce urease, and did not produce either type of egg-yolk reaction.

Nutrition. Sixteen strains were examined; one was a laboratory strain (ATCC no. 7050=N. R. Smith no. 609=CN 2202), the remainder being newly isolated. A temperature of $45^{\circ}$ was found preferable for these organisms. All strains grew well in the casein basal medium supplemented with aneurin and biotin; the ammonia basal medium could not replace the casein medium. Thus all strains could not use ammonia as sole source of nitrogen and required amino-acids. There was some evidence that not all strains required both aneurin and biotin, but that a few synthesized one or other of these compounds, or variants with these abilities were rather easily selected during subcultivation.

There was no evidence for any growth factor requirements other than aneurin and biotin. This point was examined in some detail, since Cleverdon et al. (1949a) reported a strain of B. coagulans (N. R. Smith, no. 27) which grew when aneurin, biotin and nicotinic acid were added to a basal caseinhydrolysate medium, but not in the absence of any one of these three essential metabolites. Our casein basal medium was tested for nicotinic acid (or equivalent material) by attempting to grow a strain of Proteus vulgaris in it. This organism did not grow until the medium was supplemented by nicotinic acid. The medium therefore was effectively free from nicotinic acid. By the criterion of ability to grow on this casein medium supplemented by aneurin and biotin but without nicotinic acid, it can therefore be said that none of the fifteen newly isolated strains of $B$. coagulans examined, nor ATCC no. 7150, required nicotinic acid as a nutrient.

\section{Bacillus firmus}

Only three new isolates were obtained from soil. These were studied in detail, together with two strains from collections. Smith et al. (1946) considered the more important differential characters to be: morphology; no growth at pH 6.0; character of the growth on nutrient agar and glucose nutrient agar; failure to utilize inorganic nitrogen; hydrolysis of starch, gelatin and casein; failure to produce urease.

Our five strains had these characters. Smith et al., however, felt that this organism was difficult to classify since it has a morphology intermediate between that of the $B$. subtilis group and the $B$. circulans/brevis group, and had some of the physiological characteristics of $B$. brevis and $B$. sphaericus. In only one of our five strains were the sporangia slightly swollen, and we feel that the organism is, morphologically, clearly in group 1. The physiological activity of these strains also was quite different from that of $B$. sphaericus, which is relatively inert. $B$. firmus ferments glucose, hydrolyses starch, gelatin and casein and sometimes reduces nitrate, while $B$. sphaericus only hydrolyses gelatin. We also found $B$. firmus unable to grow anaerobically, thus separating it from the $B$. circulans group. 
Nutrition. A preliminary examination indicated that the nutritional requirements were complex.

\section{Bacillus lentus}

Two strains of $\boldsymbol{B}$. lentus were isolated from soil; these were studied, together with one laboratory strain (Gibson's no. 165). Smith et al. (1946) studied one strain and provisionally allocated the organism to morphological group 1, near to $B$. firmus. These three strains of $B$. lentus differed from $B$. firmus in producing urease, not hydrolysing gelatin or casein, and not reducing nitrate; they were not able to grow anaerobically. Preliminary experiments indicated complex nutritional requirements.

\section{Bacillus firmus, Bacillus lentus and related organisms}

Of eleven new isolates which were clearly in the $\boldsymbol{B}$. firmus-B. lentus group, five conformed to the type description of one or other species (see above), but six could not be classified. They differed from either of the two species in more than one character such as hydrolysis of starch, casein or gelatin and reduction of nitrate. This represents a high proportion of isolates which could not be classified and is different from our experience with other species.

\section{Bacillus megatherium}

Twelve new isolates were examined in detail. Smith et al. (1946) considered the following characters as the more important in identifying this species: the well-known morphological appearance of Gram-stained preparations, in particular a width of vegetative rod greater than $0.9 \mu$.; negative VP reaction; production of acid without gas from glucose, arabinose and usually xylose; hydrolysis of starch; heavy growth on glucose nitrate agar.

In our experience growth on glucose nitrate agar was of little diagnostic value, strain variation being as great as species variation. Four of our twelve new isolates failed to grow on glucose nitrate agar, and two strains failed to hydrolyse starch; otherwise they agreed with the above characters.

Two additional tests were of great value in differentiating $B$. megatherium from $B$. cereus. $B$. megatherium was unable to grow anaerobically and did not produce any egg-yolk reaction, whereas $B$. cereus gives positive reactions in these tests (Table 2).

Nutrition. All eleven strains examined (eight new isolates and three laboratory strains including ATCC no. $8245=N$. R. Smith no. $234=C N 2193$ ) grew on the ammonia basal medium alone; no growth factors were needed (Table 2).

\section{Bacillus cereus}

Twelve new isolates were examined in detail. Smith et al. (1946) considered the following characters as the more important in identifying this species: the morphology, including a width of vegetative rod greater than $0.9 \mu$.; colonial appearance; positive VP reaction; production of acid from glucose but not from arabinose and xylose; hydrolysis of starch. 
Table 2. Nutritional and other characters of Bacillus megatherium, B. cereus and intermediates

\begin{tabular}{|c|c|c|c|c|c|c|}
\hline \multirow[b]{2}{*}{ Organism } & \multicolumn{4}{|c|}{$(+=$ positive reaction; $(+)=$ variable reaction. $)$} & \multicolumn{2}{|c|}{ Nutrition } \\
\hline & $\begin{array}{l}\text { Voges- } \\
\text { Proskauer } \\
\text { reaction }\end{array}$ & $\begin{array}{l}\text { Acid from } \\
\text { arabinose } \\
\text { and } \\
\text { xylose }\end{array}$ & $\begin{array}{c}\text { Egg-yolk } \\
\text { reaction } \\
\text { (lecithinase) }\end{array}$ & $\begin{array}{l}\text { Anaerobic } \\
\text { growth }\end{array}$ & $\begin{array}{l}\text { Ammonia } \\
\text { used }\end{array}$ & $\begin{array}{l}\text { Amino- } \\
\text { acids } \\
\text { required }\end{array}$ \\
\hline $\begin{array}{l}\text { B. megatherium, } \\
11 \text { strains }\end{array}$ & - & + & - & - & + & - \\
\hline$B$. cereus, 18 strains & + & - & + & + & . & + \\
\hline $\begin{array}{l}\text { B. cereus var. mycoides, } \\
10 \text { strains } \\
\text { Intermediates: }\end{array}$ & + & - & + & + & . & + \\
\hline CN 786 & $+(4 \mathrm{da}$ & ys) & - & - & + & - \\
\hline CN 2496 & $(+)$ & - & - & - & + & - \\
\hline CN 2481 & + feebl & + & + & + & . & + \\
\hline CN 2502 & + & + & + & + & . & + \\
\hline CN 2509 & + & + & + & + & . & + \\
\hline CN 2513 & + & + & + & + & . & + \\
\hline
\end{tabular}

These characters were found in all our strains and furthermore all the $B$. cereus strains, in contradistinction to $B$. megatherium, grew anaerobically and produced the characteristic egg-yolk reaction, which has been shown by McGaughey \& Chu (1948) to be due to a lecithinase C.

Nutrition. Thirteen strains were examined (eleven new isolates and two laboratory strains including ATCC no. $6630=N$. R. Smith no. $305=C N$ 2194). None of them utilized ammonia as sole nitrogen source. All grew on the hydrolysed casein medium, which could be replaced by certain mixtures of amino-acids. There was no evidence of any other nutrient requirements (i.e. for growth factors). Several strains were grown with mixtures of amino-acids. Three strains (CN 2194, 2503 and 2504) grew on a mixture of seven amino-acids (medium 7AA), namely, L-asparagine, DL-proline, L-leucine, DL-alanine, Lglutamic acid, DL-serine and DL-methionine.

Eight strains (CN 2484, 2501, 2505, 2506, 2507, 2508, 2511, 2512 and 2810) grew on a mixture containing fourteen amino-acids (medium 14AA), namely, DL-alanine, DL-aspartic acid, L-arginine, L-glutamic acid, glycine, L-histidine, L-leucine, DL-methionine, DL-phenylalanine, DL-serine, DL-tryptophan, L-tyrosine, L-cysteine and DL-valine.

The requirements for specific amino-acids in these mixtures were not further analysed. Ability to grow on these mixtures, however, substantiates the conclusion that none of the strains examined required any of the vitamin B group of essential metabolites.

Among the laboratory strains one (now CN 2810), originally labelled $B$. subtilis, proved unable to grow on ammonia medium and required amino-acids, which made it unlike characteristic subtilis strains. Other diagnostic tests then proved it to be $\boldsymbol{B}$. cereus, producing, for example, a positive typical egg-yolk reaction. Here again apparently anomalous nutritional requirements led to a correct identification. The results with all strains are summarized in Table 2. 


\section{Bacillus cereus var. mycoides}

Twelve new isolates were examined in detail. They differed from $B$. cereus only in the rhizoid nature of the colony on nutrient agar. With our strains $B$. cereus showed a slight preference for growth at $37^{\circ}$ as against $28^{\circ}$, whereas the $B$. cereus var. mycoides strains showed a marked preference for $28^{\circ}$ and grew poorly or not at all at $37^{\circ}$.

$B$. cereus var. mycoides when incubated at room temperature in nutrient broth and then plated on nutrient agar produced a number of colonies indistinguishable from $\boldsymbol{B}$. cereus. One strain was examined in more detail. The original culture of $\boldsymbol{B}$. cereus var. mycoides gave typical colonies, grew well at $28^{\circ}$ and did not grow at $37^{\circ}$, whereas the cereus-like variant obtained from it grew slightly better at $37^{\circ}$ than at $28^{\circ}$. On subcultivation in casein basal medium or a 14-amino-acid mixture (medium 14AA) the typical growth of var. mycoides, as a submerged pellicle which remained intact on agitating the culture tubes, changed with some strains to a diffuse growth like that of typical strains of $B$. cereus under the same conditions. The change from the mycoides to the cereus characters was not further studied. Nutritionally (see below) and in all other respects except the typical colonial growth on plates and in liquid media, these mycoides strains were identical with the cereus strains. The opinion of Smith et al. (1946) that ' $B$. mycoides' is a rhizoid variant of $B$. cereus is supported by our observations.

Nutrition. All ten strains examined (including ATCC no. $6463=\mathbf{N}$. R. Smith no. $306=\mathrm{CN} 2195$ and nine new isolates) did not grow on the ammonia basal medium but grew in the casein basal medium without added growth factors. Some strains were grown on the 14-amino-acid mixture (medium 14AA) but the amino-acid requirements were not further analysed. Thus the nutrient requirements were satisfied by the media suitable for $B$. cereus (see Table 2).

\section{Bacillus megatherium/cereus intermediates}

A number of new isolates were classified as $B$. megatherium/cereus intermediates since they were aberrant either in the VP reaction or in the fermentation of arabinose and xylose. These intermediates fell into two groups: those which did not grow anaerobically and did not produce any egg-yolk reaction (i.e. were like megatherium) and those which grew anaerobically and produced a typical cereus-like egg-yolk reaction. It seemed rational therefore to classify these intermediates as $\boldsymbol{B}$. megatherium or $\boldsymbol{B}$. cereus respectively. We did not find a strain which grew anaerobically and failed to produce the typical cereuslike egg-yolk reaction, or one which did not grow anaerobically but did produce a cereus-like egg-yolk reaction. The specific nutritional requirements supported this separation (see Table 2).

Nutrition. Six strains (five new isolates) which were classified as megatherium/cereus intermediates had the nutritional characters summarized in Table 2, two being like $B$. megatherium in using ammonia, and the other four requiring amino-acids like $B$. cereus. 


\section{Bacillus polymyxa}

Twelve new isolates from soil were studied in detail. Smith et al. (1946) considered the following characters as the more important in identifying this species: the morphology; positive VP reaction; fermentation of glucose, arabinose and xylose, with the production of gas; hydrolysis of starch. These characters were found with our new isolates. Additional characteristics of the organism were an ability to grow anaerobically and to give a positive Gibson \& Abdel-Malek test.

Nutrition. Katznelson \& Lochhead (1944) examined the nutrient requirements of eighty-two strains of $B$. polymyxa and found that all grew on an ammonia basal medium plus biotin. The thirteen newly isolated strains we examined showed these same nutrient requirements. Since we were mainly concerned with minimal requirements we did not examine the adjuvant effect of other nitrogen sources and growth factors as did Katznelson \& Lochhead. We did not find an authentic B. polymyxa, i.e. as characterized according to Smith et al. (1946), which grew in ammonia basal medium without biotin, nor one which did not grow on the ammonia medium when it was supplemented with biotin. We have not yet examined the replacement of biotin by possible precursors in its biosynthesis, nor the effect of oleic acid, etc. Ability to use ammonia + biotin appears to be a typical character of $B$. polymyxa.

\section{The Bacillus macerans-circulans-alvei group}

The organisms classified under these names in the work of Smith et al. (1946) are less clearly differentiated, or are differentiated by less striking characters, than are many other species in the genus. We encountered many strains with characters intermediate between pairs of species, as defined. This holds for the nutritional patterns as well as for the other characters. But often the nutritional patterns within groups of intermediates did not correspond with a subdivision based on some other character, unlike the subtilis/pumilus and megatherium/cereus intermediates, where the respective nutritional patterns were regularly associated with other species characters. For this reason, therefore, the general bacteriological findings and the nutritional findings with the aberrant and intermediate strains are reported separately in Tables 3 and 4. It remains to be seen whether this non-correspondence of physiological and nutritional characters in the intermediate strains and the greater heterogeneity of nutritional requirements of typical strains within a given species, is really the reflexion of imperfect differentiation or is to be considered as a natural feature characterizing the group as a whole.

In the following sections the strains are described as much as possible under species groupings, all strains under a given species name agreeing with the species description. The exceptional strains are described with the nearest species or as frank intermediates. 
Table 3. The relationship between Bacillus macerans, B. circulans, B. alvei, B. laterosporus and intermediates

(All these organisms belong to the Smith, Gordon \& Clark morphological group 2 and are facultative aerobes. They are differentiated by the reactions shown below.)

\begin{tabular}{|c|c|c|c|c|c|c|c|}
\hline \multirow[b]{2}{*}{ Species } & \multicolumn{3}{|c|}{ Acid or gas from } & \multirow{2}{*}{$\begin{array}{l}\text { Voges- } \\
\text { Proskauer } \\
\text { reaction }\end{array}$} & \multicolumn{3}{|c|}{ Hydrolysis of } \\
\hline & Glucose & Arabinose & Xylose & & Starch & Casein & Gelatin \\
\hline $\begin{array}{l}\text { B. macerans } \\
\text { B. circulans } \\
\text { B. alvei } \\
\text { B. laterosporus }\end{array}$ & $\begin{array}{l}+ \text { gas } \\
+ \\
+ \\
+\end{array}$ & $\begin{array}{l}+ \text { gas } \\
+ \\
- \\
-\end{array}$ & $\begin{array}{l}+ \text { gas } \\
+ \\
- \\
-\end{array}$ & $\begin{array}{l}- \\
\pm \\
+\end{array}$ & $\begin{array}{l}+ \\
+ \\
+ \\
+\end{array}$ & $\begin{array}{l}- \\
\dot{t} \\
\dot{I}\end{array}$ & $\begin{array}{l}+ \\
+ \\
+ \\
+\end{array}$ \\
\hline Intermediate strains: & & & & & & & \\
\hline $\begin{array}{l}\text { CN 2628, 2629, } 2718 \\
\text { CN 2755, 2756 } \\
\text { CN 2807 } \\
\text { CN 2482 } \\
\text { CN 2589, } 2620\end{array}$ & $\begin{array}{l}+ \\
+ \\
+ \\
+ \\
+\end{array}$ & $\begin{array}{l}+ \\
+ \\
+ \\
+\end{array}$ & $\begin{array}{l}+ \\
+ \\
+\end{array}$ & $\begin{array}{l}- \\
\overline{-} \\
+ \\
+\end{array}$ & $\begin{array}{l}+ \\
+ \\
+ \\
+\end{array}$ & $\begin{array}{l}- \\
\bar{t} \\
-\end{array}$ & $\begin{array}{l}- \\
+ \\
+ \\
-\end{array}$ \\
\hline
\end{tabular}

Table 4. Nutritional requirements of Bacillus macerans, B. circulans, B. alvei strains and intermediates

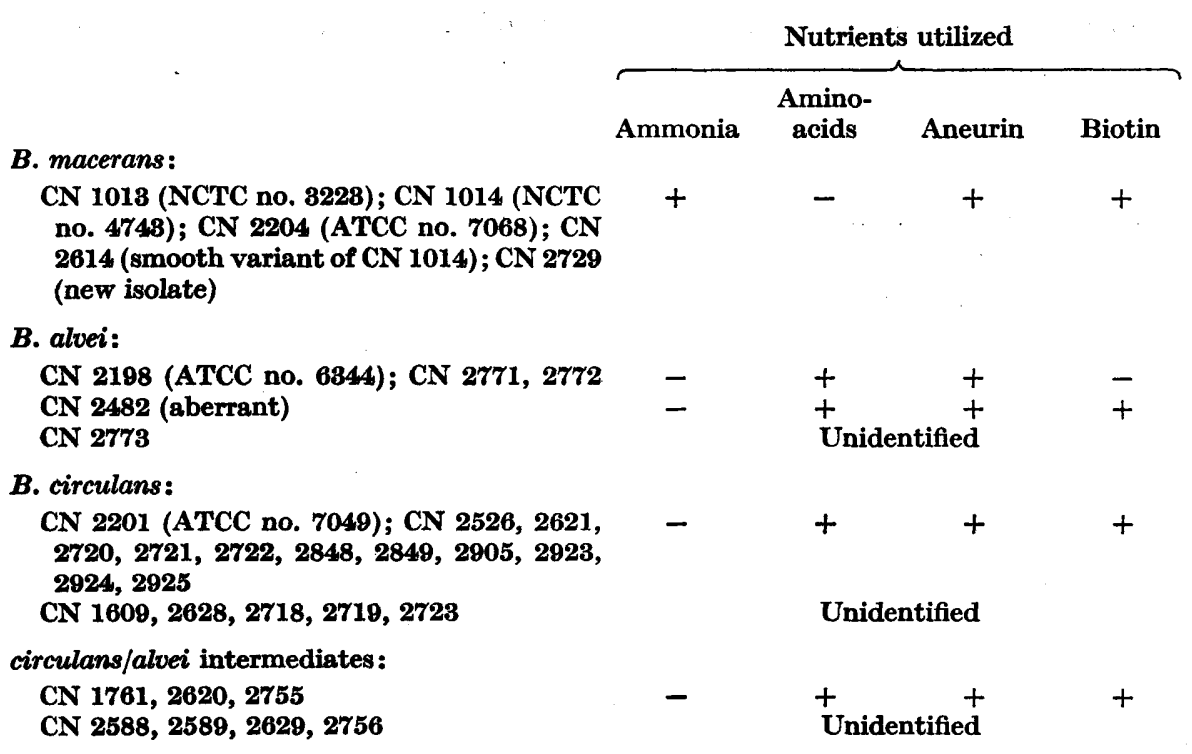

Bacillus macerans

Only one strain of $B$. macerans was isolated from soil and was studied with four laboratory strains. The description of Smith et al. (1946) was confirmed with these five strains. We also noted the ability of these strains to grow anaerobically and to give a weak positive Gibson \& Abdel-Malek test. We also observed, with our technique, considerable irregularity in the production of gas from sugars. 
Nutrition. Katznelson (1944) compared the nutritional requirements of $B$. polymyxa, B. macerans and one strain of ' $B$. acetoaethylicus' with a view to their differentiation; all his eighty-two strains of $B$. polymyxa grew on ammonia + biotin (cf. Katznelson \& Lochhead, 1944) and the three strains of $B$. macerans and the one strain of ' $B$. acetoaethylicus' which he examined grew only with the further addition of aneurin. In Bergey's Manual (1948), following Porter, McClesky \& Levine (1937), B. acetoaethylicum (originally described by Northrop, Ashe \& Senior, 1919) is regarded as a synonym for B. macerans.

Only one of our five strains was newly isolated, and one (CN 2614) was a smooth variant derived from CN 1014 (NCTC 4743) which showed some difference from the parent organism as regarded sugar fermentations. The four laboratory strains and the new isolate all grew on ammonia + biotin + aneurin but not on the ammonia medium with aneurin or biotin alone. This is in agreement with Katznelson (1944). These five strains were quite distinct nutritionally from all other strains in this group of species in being able to utilize the ammonia basal medium and in not requiring any amino-acids.

\section{Bacillus circulans}

Fifteen new isolates were studied in detail. The chief diagnostic characters of $B$. circulans are: negative VP reaction; fermentation of glucose and usually arabinose and xylose; hydrolysis of starch and gelatin but not casein. These characters, described by Smith et al. (1946), were possessed by all our strains. In addition they were able to grow anaerobically, did not give a positive Gibson \& Abdel-Malek test or any egg-yolk reaction. The ability to grow anaerobically separates $\boldsymbol{B}$. circulans from the $\boldsymbol{B}$. firmus-B. lentus group and from $B$. brevis. The failure to give a restricted egg-yolk reaction separates it from $B$. alvei. However, the close relationship between $B$. macerans, $B$. circulans and $B$. alvei, commented on by Smith et al. (1946), was evident and many intermediate types were isolated.

Nutrition. Many strains of $B$. circulans were difficult to grow, and we are not satisfied that we have yet found the best basal medium for revealing the nutritional requirements. Nevertheless, the positive responses to certain essential metabolites may be considered valid.

Eighteen strains classified as $B$. circulans according to Smith et al. (1946) were examined; these included two laboratory strains (one being ATCC no. $7049=$ N. R. Smith no. $358=$ CN 2201 ), the remaining sixteen being newly isolated.

The nutritional requirements of twelve of these strains were satisfied by casein basal medium + biotin + aneurin; but the growth of six strains was irregular on this medium, nor was it improved by the addition of riboflavin, pyridoxin, folic acid, pantothenic acid, or nicotinic acid, either singly or in combination. Whether the bad and irregular growth of these strains was due to their requiring some biosynthetically 'higher' derivative of one of these substances (e.g. coenzyme I instead of nicotinic acid, pyridoxamine or pyridoxal instead of pyridoxin), or for other specific nutrients, or whether some 
physico-chemical requirement (e.g. salt composition or concentration) was not satisfied, has not yet been determined. A few strains, e.g. CN 2848 and 2925, were made to grow with ammonia instead of the casein hydrolysate, but these ammonia-utilizing cultures had probably been selected during subcultivation; the parent cultures required amino-acids. Table 4 summarizes the results with B. circulans.

\section{Bacillus alvei}

Only a few strains of $B$. alvei were studied, namely one laboratory strain, two strains from honeycombs infected with European foul-brood (received from Dr E. Schreiner), and one isolated by us from soil. As described by Smith et al. (1946) this species is distinguished from $B$. circulans by: positive VP reaction; failure to ferment arabinose or xylose; ability to hydrolyse casein. The four strains we examined produced a restricted type of egg-yolk reaction and grew anaerobically.

Nutrition. Katznelson \& Lochhead (1947) found that ten strains of B. alvei required aneurin when grown in a hydrolysed casein medium or in a mixture of amino-acids. B. para-alvei, isolated from bee larvae affected with 'parafoulbrood' disease (Burnside, 1932; Burnside \& Foster, 1935), was considered by Smith et al. (1946) to be identical with $B$. alvei. Three strains examined by Katznelson \& Lochhead (1947) grew in certain amino-acid mixtures without added aneurin, but not in the acid-hydrolysed casein medium without aneurin. Thus the B. para-alvei and $B$. alvei strains of Katznelson \& Lochhead differed nutritionally and fell into two groups distinguished by the requirement of $B$. alvei for aneurin when growing on the hydrolysed casein medium. Later Katznelson (1947) found that $B$. para-alvei grew abundantly in mixtures of fifteen to eighteen amino-acids with aneurin and moderately in the same aminoacid mixtures without aneurin. Certain omissions from the amino-acid mixtures greatly affected growth in the absence of aneurin; omission of phenylalanine, valine and isoleucine much decreased the growth and omission of cystine stopped it completely. The cystine could be replaced by certain sulphurcontaining substances, e.g. glutathione, homocystine and homocysteine, thiolacetate or thiosulphate, but not by methionine, thiourea, thiouracil or sulphite. It was suggested that perhaps the active sulphur-containing compounds were utilized as precursors in the biosynthesis of aneurin.

We examined only five strains of $B$. alvei (ATCC no. $6344=N$. R. Smith no. $662=\mathrm{CN} 2198$ ), three new isolates, and one other new isolate (CN 2482) which was aberrant (see Table 3). These strains, with the exception of CN 2482 and 2773 , grew on the casein medium when aneurin was added but not without it. Ammonia could not be substituted for the hydrolysed casein but growth was obtained on certain mixtures of amino-acids, again only in the presence of aneurin, biotin not being required as a nutrient. The aberrant strain CN 2482 required both biotin and aneurin as supplements to the casein basal medium. In this respect, therefore, this organism resembled some circulans strains from which, however, it was distinct on other grounds. The remaining strain, CN 2773, appeared to have more complex requirements than the other alvei strains and was not grown satisfactorily. 
Our results (see Table 4), therefore, as far as they go, agree fairly well with those of Katznelson \& Lochhead; we have not yet investigated the specificity of the aneurin requirements.

Thus the well-defined $B$. alvei strains differed from $B$. circulans in that the former did not require biotin as a nutrient, whereas the majority of the $B$. circulans strains required at least aneurin and biotin, and some strains had even more complex requirements.

\section{Bacillus macerans-circulans-alvei group; aberrant and intermediate strains}

$B$. macerans is distinguished from $\boldsymbol{B}$. circulans by its ability to produce acid and gas from sugars, whereas $B$. circulans only produces acid (Table 3). We examined three strains of $B$. macerans from culture collections, i.e. $\mathrm{CN} 1013$, 1014 and 2204 (=ATCC no. 7068). Peptone water was the basal medium used. Strain CN 1013 produced acid and gas from glucose, lactose, sucrose, mannitol, arabinose, xylose, rhamnose, raffinose, salicin, dextrin, fructose and galactose, but acid only from maltose. Strain CN 1014 differed from CN 1013 in producing acid and gas from maltose but acid only from arabinose. Strain CN 2204 differed from $\mathrm{CN} 1013$ in producing acid and gas from sucrose, mannitol and raffinose but acid only from the other sugars. From strain CN 1014, which was mainly rough, a smooth variant (CN 2614) was selected which differed from the parent strain in producing acid only from glucose, lactose, sucrose, raffinose, salicin and dextrin; acid and gas were produced from the remaining sugars. A strain newly isolated from soil (CN 2729) produced acid and gas from lactose, mannitol, xylose, inulin, fructose, raffinose, arabinose, rhamnose, trehalose, and dextrin but not from glucose, sucrose, maltose or salicin.

All these strains, however, were like $B$. macerans in their nutritional requirements'(see p. 527). However, one new isolate (CN 2629) from soil gave reactions similar to $B$. macerans or $B$. circulans but produced acid and gas from salicin and glycerol only; with the other sugars only acid was produced; this strain nutritionally was not a macerans (see Tables 3 and 4).

The foregoing results suggest that the fermentation of sugars with the production of gas is not only variable in the macerans group, but strains which are not $B$. macerans and are more nearly related to $B$. circulans may produce acid and gas from some sugars.

Some emphasis has been placed on the hydrolysis of casein and gelatin as characterizing $B$. circulans. In Table 3 four strains (CN 2628, 2629, 2718 and 2807) are classified as intermediates, since they either did not hydrolyse casein or gelatin, or hydrolysed both casein and gelatin. However, we feel that these strains should be properly classified as $B$. circulans, and the ability to hydrolyse gelatin and casein regarded as variable with this species.

We also found a number of strains, otherwise like $B$. circulans, which fermented neither arabinose or xylose; they also were classified as $B$. circulans. Also, as shown in Table 8, two strains (CN 2755 and 2756) were isolated which did not produce acid from arabinose or xylose. These strains, together with 
those strains (CN 2589 and 2620) which were VP positive and fermented both arabinose and xylose, were classified as $B$. circulans/alvei intermediates. One strain (CN 2482) was isolated which was similar to $B$. alvei, except that it failed to hydrolyse starch, casein or gelatin; it was nutritionally aberrant also (see Table 8).

Nutrition. Six strains (five newly isolated) which were intermediates in properties between circulans and alvei were examined. Three (CN 2588, 2589 and 2756) were difficult to grow on defined media and nothing can be said about them. The remaining three strains (CN 1761, 2620 and 2755) grew on casein basal medium + aneurin + biotin. One of them (CN 2755) grew in ammonia + aneurin + biotin after prolonged subcultivation, probably owing to selection of an amino-acid synthesizer; the parent culture required hydrolysed casein. Thus three of these intermediate strains resemble $B$. circulans nutritionally, while the other three probably have more complex nutrient requirements and are thus not like alvei strains. The results are summarized in Table 4.

It must be emphasized that the macerans-circulans-alvei group is outstanding in the genus for the number of aberrant and intermediate strains encountered.

\section{Bacillus brevis}

Seven new isolates were studied in detail. Smith et al. (1946) considered the following characters as the more important in identifying this species: morphology; production of an alkaline $\mathrm{pH}$ in glucose broth after 7 days' incubation; negative VP reaction; production of acid from glucose and sometimes from arabinose and xylose; no hydrolysis of starch; hydrolysis of gelatin and casein. All our strains had these properties (with two minor exceptions), would not grow anaerobically, thus distinguishing them from the circulans group, and all produced urease. Smith et al. use the utilization of citrate in their Key in separating $B$. brevis from $B$. laterosporus, although they mention it is a variable character. We found the utilization of citrate variable in the strains of $B$. brevis we examined.

Two new isolates from soil (CN 2833 and 2932) were similar to $B$. brevis except that the $\mathrm{pH}$ in glucose broth after 7 days was less than $8 \cdot 0$. Both grew aerobically only, and were therefore considered $\boldsymbol{B}$. brevis.

Nutrition. Ten strains were examined (nine newly isolated and strain ATCC no. $8185=$ N. R. Smith no. $751=C N$ 2203). Of the nine new isolates two (CN 2833 and 2932) were slightly aberrant (see above). All strains, with the exception of the slightly aberrant $\mathrm{CN}$ 2932, grew on the casein basal medium without added growth factors. Strain CN 2932, however, was also nutritionally aberrant growing only when aneurin, biotin and nicotinic acid were added to the casein basal medium. Thus the ATCC strain and eight new isolates were homogeneous in nutritional requirements; only one strain, $\mathrm{CN} 2932$, was different and that markedly. A nutritional requirement satisfied by nicotinic acid has been observed among mesophilic organisms of the genus Bacillus only for some strains of $B$. pasteurii (see p. 532) and for one strain of $B$. coagulans (Cleverdon et $a l .1949 a$ ), and is thus apparently very unusual. Cleverdon et al. $(1949 b)$, however, found two groups of stenothermophilic $\left(55-65^{\circ}\right)$ strains of 
Bacillus which required nicotinic acid. Apart from its peculiar nutritional requirements CN 2932 clearly belongs more to $B$. brevis than to any other species.

Bacillus sphaericus and Bacillus sphaericus var. fusiformis

Twelve new isolates which were considered typical $B$. sphaericus were isolated from soil and studied in detail. Smith et al. (1946) gave the following characters as the more important in identifying this species; the morphology, including bulging of the sporangium by a thick-walled spherical spore; growth on nutrient agar at pH 7.4 and 6.0; growth in $4.0 \% \mathrm{NaCl}$ broth; hydrolysis of gelatin; negative VP reaction; no fermentation of sugars; no reduction of nitrate; no hydrolysis of starch of casein. All our twelve new isolates conformed to these characters.

Smith $e$ al. described three varieties which differed from $B$. sphaericus as follows: $B$. sphaericus var. rotans: no growth on nutrient agar at $\mathrm{pH} 6.0$ or in $4.0 \% \mathrm{NaCl}$ broth; maximum temperature for growth $35^{\circ} ; B$. sphaericus var. fusiformis: produces urease; $B$. sphaericus var. loehnisii: no growth at $\mathrm{pH} 6 \cdot 0$ and produces urease.

We did not isolate any strains of $B$. sphaericus var. rotans, but twelve new isolates each of $\boldsymbol{B}$. sphaericus var. fusiformis and $\boldsymbol{B}$. sphaericus var. loehnisii were obtained from soil. These strains conformed to the descriptions given by Smith et al. (1946); they also failed to grow anaerobically.

Nutrition. Only strains of B. sphaericus and B. sphaericus var. fusiformis were examined critically, and the results with these two organisms are conveniently reported together. Hitherto their differentiation has rested upon the absence of urease from $B$. sphaericus and its presence in $B$. sphaericus var. fusiformis. We examined nine strains of $B$. sphaericus (eight new isolates and ATCC no. $10208=N$. R. Smith no. $966=\mathrm{CN} 2205$ ), and ten strains of B. sphaericus var. fusiformis (eight new isolates and two laboratory strains, one being ATCC no. $7055=\mathrm{CN} 2209$ ). The ten strains of $B$. sphaericus var. fusiformis were uniform in that they would not grow on the casein basal medium in the absence of aneurin and biotin, but grew when both were added, neither being effective alone.

On the other hand, six out of nine strains of $B$. sphaericus grew on casein basal medium with added aneurin alone. The remaining three strains of B. sphaericus (CN 2485, 2546 and 1652) grew with aneurin + biotin on the casein basal medium, but not with either of these substances singly, i.e. these three strains were nutritionally like the strains of fusiformis. They were repeatedly tested for urease but were always negative, i.e. they had the sphaericus diagnostic character. It was possible to replace the hydrolysed casein by a mixture of seven amino-acids (medium $7 \mathbf{A A}$ ) for many of the strains of $B$. sphaericus and $B$. sphaerieus var. fusiformis; medium $14 \mathrm{AA}$ was adequate for all strains of $B$. sphaericus and B. sphaericus var. fusiformis with one exception. Strains differed in the dispensability of certain amino-acids but the mixture of fourteen amino-acids was adequate for most of them.

Only one strain each of $B$. sphaericus var. loehnisii and var. rotans 
were examined; their nutrition appeared to be more complex than that of B. sphaericus var. fusiformis.

\section{Bacillus pasteurii}

Twelve new isolates of $B$. pasteurii were isolated from soil. Smith et al. (1946) considered the following characters as the more important in identifying $B$. pasteurii: the morphology, including bulging of the sporangium by a thickwalled spherical spore; inability to grow on nutrient agar; growth on nutrient agar containing $2.0 \%$ urea; the formation of urease; reduction of nitrate to nitrite; growth in $4.0 \% \mathrm{NaCl}$ broth (with $1.0 \%$ urea); hydrolysis of gelatin but not of starch; failure to ferment sugars. This description was confirmed with all the twelve new isolates.

With most strains, after 4- 7 days in the anaerobic jar, many tiny colonies (diameter $c .0 \cdot 1 \mathrm{~mm}$. or less) were observed.

Nutrition. The work on the differentiation and classification of organisms of the $B$. pasteurii group by Gibson included some studies of nutritional requirements (Gibson, 1934a, $b ; 1935 a, b$ ). We examined ten strains of $B$. pasteurii as defined by Smith et al. (1946) (nine new isolates and ATCC no. 6452=N. R. Smith no. 674 $=$ CN 2199).

The nutritional requirements of these strains were rather more heterogeneous than in most of the other species we studied (Table 5). Furthermore,

Table 5. Nutritional requirements in Bacillus pasteurii

(Basal medium adjusted to pH 8.5, incubation at $28^{\circ}$.)

\begin{tabular}{|c|c|c|c|c|c|c|}
\hline \multirow[b]{2}{*}{ Strain } & \multirow{2}{*}{$\begin{array}{l}\text { Number } \\
\text { of } \\
\text { strains }\end{array}$} & \multicolumn{5}{|c|}{ Nutrients required } \\
\hline & & Ammonia & $\begin{array}{l}\text { Amino- } \\
\text { acids }\end{array}$ & Aneurin & Biotin & $\begin{array}{l}\text { Nicotinic } \\
\text { acid }\end{array}$ \\
\hline $\begin{array}{l}\text { CN 2199* (=ATCC no. } \\
6452) ; \text { CN 2715, 2804, } \\
2805\end{array}$ & 4 & + & + & + & - & + \\
\hline CN 2716, 2717 & 2 & + & + & + & + & - \\
\hline CN 2713,2803 & 2 & - & + & + & - & + \\
\hline CN 2710,2712 & $\mathbf{2}$ & - & + & + & + & - \\
\hline
\end{tabular}

* CN 2199. Clear-cut results as to the requirement or otherwise for biotin in presence of nicotinic acid were difficult to obtain with this strain (see text, p. 533).

some strains had a nutrient requirement satisfied by nicotinic acid. Apart from the aberrant strain CN 2932 of $B$. brevis (see p. 530) none of our strains of mesophilic species in the genus Bacillus had a nutritional requirement which could be satisfied by nicotinic acid, i.e. all appeared able to satisfy their nicotinic acid requirements by synthesis. The only other reports of nicotinic acid as a nutrient for an organism of the genus Bacillus are those of Cleverdon et al. $(1949 a)$ who had one strain (eurithermophilic, $37-55^{\circ}$ ) of $B$. coagulans which required nicotinic acid, and the stenothermophilic $\left(55-65^{\circ}\right)$ strains of Bacillus reported by the same authors $(1949 b)$.

The ten strains of $B$. pasteurii examined grew best at $28^{\circ}$ and at $\mathrm{pH} 8.5$ in the casein basal medium supplemented by various essential metabolites. Ammonia basal medium did not replace the casein basal medium; thus an 
inability to synthesize at least certain amino-acids was shown by all the ten strains.

Earlier workers (Miquel, 1889, 1898; Beijerinck, 1901; quoted by Gibson, $1934, b, 1935 a$ ) found that $B$. pasteurii strains did not grow on ordinary laboratory media, e.g. peptone broth, without added urea, and it became generally accepted that the most important criterion for the recognition of $B$. pasteurii strains was inability to grow on 'ordinary' media (presumably at $c . \mathrm{pH} 7$ ) without added urea. Viehoever (1913), however, doubted the need for urea and grew strains of the organism in media simpler than those, for example, used by Beijerinck. Viehoever described growth in an ammonium carbonate mineral medium with glucose and asparagine added. Gibson $(1934 b, 1935 b)$ showed that the supposed requirement of urea as a nutrient for many strains of $\boldsymbol{B}$. pasteurii was not absolute; the urea could be replaced by ammonium ion at alkaline $\mathrm{pH}$.

Six of ten strains required ammonium ion in addition to the amino-acids of the casein hydrolysate and certain essential metabolites. Ammonium chloride, to give a final concentration of $1 \%(\mathrm{w} / \mathrm{v})$, was added to the basal medium plus essential metabolites, which was adjusted to pH 8.5. Omission of this supplement of $1 \%$ ammonium chloride prevented growth of six of ten strains; this was repeatedly confirmed. We have not compared these two sets of strains for ability to deaminate amino-acids. The existence of a requirement for ammonia, side by side with a requirement for at least certain preformed aminoacids, and an inability to use ammonia as sole $\mathrm{N}$ source, as shown by these six ammonia-requiring strains, is striking.

The essential metabolites which were found to be involved in the nutrition of these ten strains of $B$. pasteurii were aneurin, biotin and nicotinic acid. Omission of aneurin from the medium prevented the growth of all ten strains. Omission of biotin prevented the growth of four strains only, the other six strains presumably being able to synthesize this compound. Omission of nicotinic acid prevented the growth only of the six strains which did not require biotin. There was thus a correlation between the biotin and nicotinic acid requirements in that those strains which required biotin did not require nicotinic acid and vice versa. There was no correlation with the requirement for ammonia. Thus these ten strains were either biotin synthesizers or nicotinic acid synthesizers, if the interpretation be accepted that a nutrient requirement for one of the common essential metabolites is due to a defect in the biosynthesis or that essential metabolite. All strains grew better when the four components were present, namely, ammonium ion, aneurin, biotin and nicotinic acid.

Because of the great potency of biotin, clear-cut results with it were never easy to obtain, and usually involved one or more subcultures in biotin-free media, and therefore the possible selection of any biotin-synthesizers in the inocula used. With most species the results were usually unequivocal but with some of the strains of $B$. pasteurii, e.g. CN 2199, the role of biotin was less easy to determine clearly. Usually the generalization that either biotin or nicotinic acid was required as a nutrient was clearly demonstrable but with a few 
strains, notably CN 2199, it is possible that both biotin and nicotinic acid are required. The nutritional requirements of $B$. pasteurii suggest problems which require further study.

\section{DISCUSSION}

We have isolated from soil specimens of as many of the mesophilic species of the genus Bacillus as possible, and tried to name them from the descriptions of Smith et al. (1946). Of 296 strains studied 245 clearly belonged to a named species and thirty-two were clearly intermediates between two species; eight remain unidentified and it is possible that further study will clarify their relationship to a described species. Eleven new isolates are believed to represent a previously undescribed species (cf. Proom \& Knight, 1950). The classification of Smith et al. has, therefore, been submitted to a severe test, and the results are a striking confirmation of the validity of their classification.

Although aberrant strains and intermediate types will always be encountered, comparative work will tend to better the description of the pattern species and consequently to decrease the number of newly isolated strains which would otherwise be classified as intermediate types. For example, we have shown that the inclusion of the egg-yolk reaction and ability to grow anaerobically among the definitive characters of $\boldsymbol{B}$. megatherium and $\boldsymbol{B}$. cereus greatly diminished the number of strains which would otherwise have been classified as intermediates.

Again, growth under strictly anaerobic conditions was useful as a diagnostic character within the genus particularly in connexion with $B$. cereus, B. licheniformis, $B$. coagulans and $B$. brevis.

Reaction with egg-yolk also has diagnostic uses apart from its importance in distinguishing between $\boldsymbol{B}$. cereus and $\boldsymbol{B}$. megatherium, where the effect is due to a lecithinase $\mathbf{C}$ produced by cereus and not by megatherium. In contradistinction to the observations of McGaughey \& Chu (1948) we found that a number of Bacillus species give a reaction with egg-yolk, but one which is restricted to the medium immediately below the growth on egg-yolk agar plates. This restricted reaction helps to distinguish $B$. subtilis from B. pumilus and $B$. circulans from other members of morphological group 2.

The survey of nutritional requirements of some 200 strains revealed on the whole a rather unexpected degree of uniformity of nutritional pattern within groups of strains. Also, named cultures and other laboratory strains in general had the same nutritional requirements as newly isolated strains of the same species. That is, the conditions of laboratory cultivation had not led to the selection of nutritional variants. Moreover, specific nutritional patterns appear to be closely related to other specific characters, and to be highly characteristic of species. In some species (e.g. B. megatherium and B. cereus) all strains, and in other species all but a few strains, had typical nutritional requirements. Exceptional strains were so infrequent that the nutritional pattern could be used as a guide at least in a preliminary allocation of new strains to their species (see Table 6). Thus organisms able to use ammonia only (without growth 
Table 6. Nutritional requirements found for the strains examined in the genus Bacillus

(The sequence of species follows that of the classification in Bergey's Manual (1948), except in group 2, where brevis has been put before alvei, and circulans after these, to emphasize increasing complexity of nutritional requirements in that group. The results for anthracis (Gladstone and Brewer et al. are included for comparison.)

\begin{tabular}{|c|c|c|c|c|c|c|}
\hline \multirow[b]{2}{*}{ Organism } & \multirow{2}{*}{$\begin{array}{c}\text { Number } \\
\text { of } \\
\text { strains }\end{array}$} & \multicolumn{5}{|c|}{ Nutrient used } \\
\hline & & Ammonia & $\begin{array}{l}\text { Amino- } \\
\text { acids }\end{array}$ & Aneurin & Biotin & $\begin{array}{l}\text { Nicotinic } \\
\text { acid }\end{array}$ \\
\hline \multicolumn{7}{|l|}{ Morphological group 1 : } \\
\hline \multirow[t]{2}{*}{ subtilis } & 26 & + & - & - & - & - \\
\hline & $\mathbf{1}$ & - & + & - & - & - \\
\hline subtilis var. aterrimus & $\mathbf{2}$ & + & - & - & - & - \\
\hline subtilis var. niger & 1 & + & - & - & - & - \\
\hline licheniformis & 12 & + & - & - & - & - \\
\hline \multirow[t]{2}{*}{ pumilus } & 19 & + & - & - & + & - \\
\hline & $\mathbf{2}$ & - & + & - & + & - \\
\hline subtilis/pumilus & 2 & + & - & - & - & - \\
\hline intermediates & 2 & + & - & - & + & - \\
\hline coagulans & $\mathbf{1 6}$ & - & + & + & + & - \\
\hline megatherium & 11 & + & - & - & - & - \\
\hline cereus & 13 & - & + & - & - & - \\
\hline cereus var. mycoides & 10 & - & + & - & - & - \\
\hline megatherium/cereus & 2 & + & - & - & - & - \\
\hline intermediates & 4 & - & + & - & - & - \\
\hline anthracis & - & - & + & + & - & - \\
\hline \multicolumn{7}{|l|}{ Morphological group 2: } \\
\hline polymyaca & 13 & + & - & - & + & - \\
\hline macerans & $\mathbf{5}$ & + & - & + & + & - \\
\hline \multirow[t]{2}{*}{ brevis } & $\mathbf{9}$ & - & + & - & - & - \\
\hline & $\mathbf{1}$ & - & + & + & + & + \\
\hline \multirow[t]{2}{*}{ alvei } & 4 & - & + & + & - & - \\
\hline & $\mathbf{1}$ & - & + & + & + & - \\
\hline \multirow[t]{2}{*}{ circulans } & 12 & - & + & + & + & - \\
\hline & 6 & . & \multicolumn{3}{|c|}{ Unidentified } & . \\
\hline circulans/alvei & $\mathbf{3}$ & - & + & + & + & - \\
\hline intermediates & $\mathbf{3}$ & - & \multicolumn{3}{|c|}{ Unidentified } & · \\
\hline \multicolumn{7}{|l|}{ Morphological group 3: } \\
\hline \multirow[t]{2}{*}{ sphaericus } & 6 & - & + & + & - & - \\
\hline & $\mathbf{3}$ & - & + & + & + & - \\
\hline sphaericus var. fusiformis & 10 & - & + & + & + & - \\
\hline \multirow[t]{4}{*}{ pasteurii } & 4 & + & + & + & - & + \\
\hline & $\mathbf{2}$ & + & + & + & + & - \\
\hline & 2 & - & + & + & + & - \\
\hline & $\mathbf{2}$ & - & + & + & - & + \\
\hline
\end{tabular}

factors) are likely to be $\boldsymbol{B}$. megatherium, B. subtilis (with varieties aterrimus and niger), or $\boldsymbol{B}$. licheniformis.

Organisms able to use casein-hydrolysate alone or amino-acid mixtures but not ammonia alone, are likely to be $\boldsymbol{B}$. cereus (with var. mycoides) or B. brevis.

Organisms able to grow with ammonia + biotin but not with ammonia alone are likely to be $B$. polymyxa or B. pumilus. 
Organisms able to grow with ammonia + biotin + aneurin, but not without one or other of these growth factors are likely to be $\boldsymbol{B}$. macerans.

Organisms unable to use ammonia + aneurin but able to use casein-hydrolysate + aneurin are likely to be B. anthracis, B. alvei or B. sphaericus (the latter not quite so certainly); an additional need for biotin is likely to indicate $B$. coagulans, B. sphaericus var. fusiformis, less common strains of $B$. sphaericus, or B. circulans.

Organisms requiring casein-hydrolysate at $\mathrm{pH} 8 \cdot 5$, aneurin, \pm ammonia, and nicotinic acid or biotin, are likely to be $B$. pasteurii.

In a few cases, already mentioned in the text, the finding of an apparently anomalous nutritional requirement led to a re-examination of what proved to be incorrectly named strains.

In connexion with the exhibition of typical nutritional patterns by groups of newly isolated strains, we do not think that the new isolates were inadvertently selected for given sets of nutritional requirements during isolation. The differential media and conditions of growth used in isolating the strains were not likely to have been selective in this sense. The media used were all nutritionally rich and complex, and therefore unlikely to have favoured the selection of good synthesizers of essential metabolites.

An interesting point seen in Table 6 is that most of the species with the more complex nutritional requirements are in morphological group 3 of Smith et al. Whereas all species in groups 1 and 2 so far examined were nutritionally satisfied by ammonia, amino-acids, aneurin and biotin, and often by only one or two of these components, the requirements for the group 3 species were considerably more complex; though $\boldsymbol{B}$. firmus and $\boldsymbol{B}$. lentus of group 1 and $\boldsymbol{B}$. laterosporus and $\boldsymbol{B}$. larvae of group 2 are likely to prove nutritionally complex. No group 3 species can utilize ammonia alone, and all require preformed aminoacids and at least two essential metabolites as growth factors. Furthermore, nicotinic acid was a requirement for more than half of the strains of $B$. pasteurii examined. Apart from a single strain of $B$. coagulans (Cleverdon et al. 1949a) and an aberrant strain of $B$. brevis, nicotinic acid is not a required nutrient for any mesophilic species of the genus except $B$. pasteurii. The requirement of nicotinic acid by groups of stenothermophilic strains of Bacillus observed by Cleverdon et al. (1949b) has already been mentioned.

What is probably a new species in morphological group 3 of the genus Bacillus (Proom \& Knight, 1950) also has equally complex nutrient requirements, eleven new isolates requiring amino-acids, aneurin, biotin and pantothenic acid. At present these strains, which represent this proposed new species, are the only ones in the genus known to require pantothenic acid.

We acknowledge with sincere thanks the painstaking and reliable technical assistance of Mr E. Harris and Miss G. M. Trim; without their work this survey would have been impossible. We wish to thank the following donors of strains used here, namely, Dr Ruth E. Gordon, Prof. S. D. Rubbo, Dr E. Schreiner, Dr W. E. van Heyningen, and the Microbiological Research Department (Ministry of Supply), Porton. 
Table 7. The differentiating characters of the species of the genus Bacillus c

The table gives the physiological and typical* nutritional characters of the strains examined in the present work. Bergey's Manual (1948), with the insertion of B. licheniformis at the appropriate place. B. anthracis, B. laterosporus completeness.

Morphological group $1=$ sporangium not swollen, or only slightly; thin-walled $\mathrm{s}$ Morphological group $2=$ sporangium swollen; thick-walled oval spore.

Morphological group $3=$ sporangium swollen; thick-walled spherical spore.

Species $\overbrace{}^{\text {Growth on }} \begin{array}{ccccc}\text { Production } \\ \text { of acid } \\ \text { inorganic } \\ \text { basal } \\ \text { medium) }\end{array}$

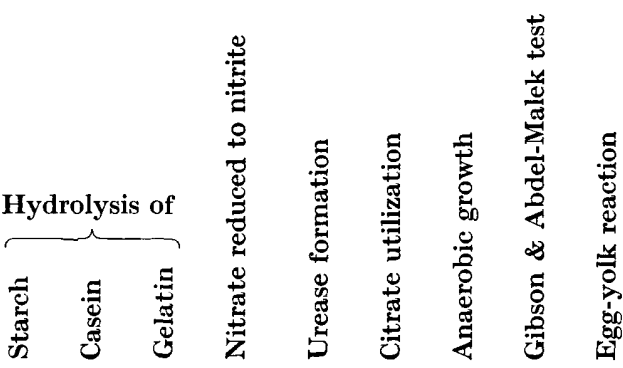

B. licheniformis

B. pumilus

B. coagulans

B. firmus

B. lentus

B. megatherium

B. cereus

B. anthracis
B. subtilis

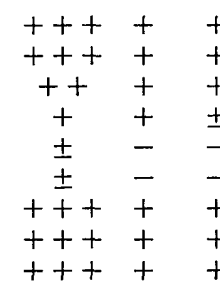

B. polymyxa

B. macerans

B. circulans

B. alvei

B. laterosporus

B. brevis

B. larvae
Morphological group 1

$\begin{array}{ccccccccc}+ & + & + & + & - & \oplus & - & - & - \\ + & + & + & + & - & \oplus & + & + & - \\ - & + & + & - & - & + & - & - & \text { tr. } R \\ + & - & - & - & - & - & + & - & - \\ + & + & + & + & - & - & - & - & - \\ - & - & - & - & + & - & - & - & \operatorname{tr} R \\ + & + & + & \ominus & \text { var. } & + & - & - & - \\ + & + & + & \oplus & \ominus & \oplus & + & - & + \\ + & + & + & \oplus & - & + & + & - & +\end{array}$

Morphological group 2

$$
\begin{array}{cccccccccccccccccccccc}
+++ & + & + & + & +G & +G & +G & + & + & + & + & + & - & - & + & + & \text { var. } R \\
\pm & + & + & + & +G & +G & +G & - & + & - & + & \text { var. } & - & - & + & \pm & \text { tr. } R \\
\pm & + & + & + & + & + & + & - & + & \oplus & \oplus & \text { var. } & \ominus & \ominus & + & - & - \\
\pm & + & + & + & + & - & - & + & + & + & + & - & - & - & + & - & +R \\
\pm & + & + & + & + & + & + & - & - & + & + & + & - & - & + & - & + \\
\pm & + & + & \oplus & \oplus & - & - & - & - & + & + & \text { var. } & - & \oplus & - & - & \text { tr. } R \\
- & \cdot & - & + & \cdot & + & . & . & - & \cdot & + & + & . & . & . & . & .
\end{array}
$$

Morphological group 3

$\begin{array}{llll}+ & + & \pm & + \\ \pm & - & - & - \\ + & + & \pm & + \\ \pm & - & - & +\end{array}$

$\begin{array}{lll}+ & - & - \\ - & - & - \\ + & - & - \\ + & - & -\end{array}$

In column 2 (growth on nutrient agar at $\mathrm{pH} 7 \cdot 5$ ) the amount of growth is recorded as follows : $+++=$ abundant gro growth; $\pm=$ thin growth; $\pm=$ poor growth; $-=$ no growth.

In the other columns the following symbols are used: $+=$ positive reaction; $\oplus=$ usually positive; tr. $=$ faint rea reaction; var. = variable; $R=$ egg-yolk reaction of 'restricted' type; $G=$ gas formation.

* Typical nutritional pattern with respect to nitrogen source and essential metabolites. For detailed analysis of $s$

$\uparrow$ Both or one of these sugars fermented. 
sined

pecies are listed in the order used in B. larvae are included for the sake of

Typical* nutritional pattern

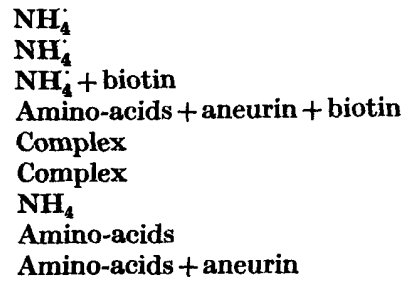

$\mathrm{NH}_{\mathbf{4}}+$ biotin

$\mathrm{NH}_{4}^{*}+$ biotin + aneurin

, Amino-acids + biotin + aneurin (or more complex)

Amino-acids + aneurin

Complex

Amino-acids

Amino-acids, aneurin, etc. (complex)

Amino-acids + aneurin (+ biotin)

Complex

Amino-acids + biotin + aneurin

Complex

Amino-acids + aneurin + biotin or nicotinic acid $\left(+\mathrm{NH}_{4}\right) ; \mathrm{pH} 8.5$

; $++=$ good growth; $+=$ moderate

n; $-=$ no reaction; $\Theta=$ usually no

ns examined see Table 6. 


\section{REFERENCES}

BeiJerinck, M. W. (1901). Zbl. Bakt. (2. Abt.), 7, 33; quoted by Gibson (1934 b).

Bergey (1948). Manual of determinative bacteriology, 6th ed. Edited by Breed, R. S., Murray, E. G. D. \& Hitchens, A. P. London: Baillière, Tindall and Cox.

Blackwood, A. C., Neish, A. C., Brown, W. E. \& Ledingham, G. A. (1947). Production and properties of 2,3-butanediol. XVII. Fermentation of glucose by strains of B. subtilis. Canad. J. Res. B, 25, 56.

Brewer, C. R., McCullough, W. G., Mills, R. C., Roessler, W. G., Herbst, E. J, \& Howe, A. F. (1946). Studies on the nutritional requirements of Bacillus anthracis. Arch. Biochem. 10, 65.

Burdon, K. L., Stokes, J. C. \& Kimbrough, C. E. (1942). Studies of the common aerobic spore-forming bacilli. I. Staining for fat with Sudan black B-Safranine. J. Bact. 43, 717.

Burnside, C. E. (1932). A newly discovered brood disease. Amer. Bee J. 72, 438.

Burnside, C. E. \& Foster, R. E. (1935). Studies on the bacteria associated with para-foul-brood. J. econ. Ent. 28, 578.

Christensen, W. B. (1946). Urea decomposition as a means of differentiating Proteus and para-colon cultures from each other and from Salmonella and Shigella types. J. Bact. 52, 461.

Cleverdon, R. C., Pelczar, Jr., M. J. \& Doetsch, R. N. (1949a). Vitamin requirements of Bacillus coagulans. J. Bact. 58, 113.

Cleverdon, R. C., Pelczar, Jr., M. J. \& Doetsch, R. N. (1949 b). The vitamin requirements of stenothermophilic aerobic sporogenous bacilli. J. Bact. 58, 523 .

Francis, A. E. \& Rippon, J. E. (1949). Bacillus polymyxa and its bacteriophages. J. gen. Microbiol. 3, 425.

Grbson, T. (1934 a). An investigation of the Bacillus pasteurii group. I. Description of strains isolated from soils and manures. J. Bact. 28, 295.

Gibson, T. (1934b). An investigation of the Bacillus pasteurii group. II. Special physiology of the organisms. J. Bact. 28, 313.

Grbson, T. (1935 a). An investigation of the Bacillus pasteurii group. III. Systematic relationships of the group. J. Bact. 29, 491.

Gibson, T. $(1935 b)$. The urea-decomposing flora of soils. I. Description and classification of the organisms. Zbl. Bakt. (2. Abt.), 92, 364 .

GrBson, T. (1944). A study of Bacillus subtilis and related organisms. J. Dairy Res. 13, 248.

Gibson, T. \& Abdel-Malek, Y. (1945). The formation of carbon-dioxide by lactic acid bacteria and Bacillus licheniformis and a cultural method of detecting the process. J. Dairy Res. 14, 35.

Gladstone, G. P. (1939). Inter-relationships between amino-acids in the nutrition of B. anthracis. Brit. J. exp. Path. $20,189$.

Hartman, T. L. (1940). The use of Sudan black B as a bacterial fat stain. Stain Tech. 15, 23.

Katznelson, H. (1944). The differentiation of Bacillus polymyxa and Bacillus macerans on the basis of their vitamin requirements. J. Bact. 48, 495.

KATzNelson, H. (1947). Substitution of thiamine by certain amino-acids in the nutrition of Bacillus para-alvei. J. biol. Chem. 167, 615.

Katzenelson, H. \& Lochhead, A. G. (1944). Studies with Bacillus polymyxa. III. Nutritional requirements. Canad. J. Res. C, 22, 273.

Katznelson, H. \& LochHead, A. G. (1947). Nutritional requirements of Bacillus alvei and Bacillus para-alvei. J. Bact. $53,83$.

Katznelson, H. \& Lochiead, A. G. (1948). The nutritional requirements of Bacillus larvae. J. Bact. 55, 763.

Knight, B. C. J. G. \& Fildes, P. (1936). A filter of Pyrex glass and stainless steel for use with Seitz filter-pads. Biochem. J. 30, 1138. 
Ledingham, G. A., Adams, G. A. \& Stanier, R. Y. (1945). Fermentation of wheat mashes by Aerobacillus polymyxa. Canad. J. Res. F, 23, 48.

LochHeAd, A. G. (1942). Growth-factor requirements for Bacillus larvae, White. J. Bact. 44, 185.

Macfarlane, R. G., Oakley, C. L. \& Anderson, C. G. (1941). Haemolysis and the production of opalescence in serum and lecitho-vitellin by the $\alpha$-toxin of Clostridium relchii. J. Path. Bact. 52, 99.

McGatghey, C. A. \& ChU, H. P. (1948). The egg-yolk reaction of aerobic sporing bacilli. J. gen. Microbiol. $2,334$.

Mreuel, P. (1889, 1898). Quoted in Gibson (1984b).

Northrop, J. H., Ashe, L. A. \& Senior, J. K. (1919). The biochemistry of Bacillus acetoethylicum with reference to the formation of acetone. J. biol. Chem. 39, 1.

Porter, R., McClesky, C. S. \& Levine, M. (1937). The fermentative sporulating bacteria producing gas from lactose. $J$. Bact. 33, 163.

Proom, H. \& Knight, B. C. J. G. (1950). Bacillus pantothenticus n.sp. J. gen. Microbiol. 4, 539.

Smith, N. R. \& ClaRk, F. E. (1937). A proposed grouping of the mesophilic, aerobic, spore-forming bacilli. Soil Sci. Soc. Amer. Proc. $2,252$.

Smith, N. R., Gordon, R. E. \& Clark, F. E. (1946). Aerobic mesophilic sporeforming bacteria. Misc. Publ. U.S. Dep. Agric. no. 559. Washington, D.C.

VIEHOEVER, A. (1913). Botanische Untersuchung harnstoffspaltender Bakterien mit besonderer Berücksichtigung der speziesdiagnostisch verwertbaren Merkmale und des Vermögens der Harnstoffspaltung. Z Zbt. Bakt. (2. Abt.), 39, 209.

(Received 8 March 1950) 